\title{
Effect of Composition on the Rheological Properties of (PC/ABS) and (PVDF/LDPE) Blends
}

\author{
F. Deri ${ }^{1}$, M. Hamui ${ }^{1}$, Imad eddin Al-Balaa ${ }^{1}$, K. Hamad $^{1}$, M. Kaseem ${ }^{1}$ and Refaat I. Nessim ${ }^{2, *}$ \\ ${ }^{1}$ Faculty of Science, Damascus Univ. Lab of Materials Rheology, Syria \\ ${ }^{2}$ Department of Chemistry, Faculty of Science, Cairo University, Egypt
}

\begin{abstract}
A series of blends of Acrylonitrile-Butadiene-Styrene (ABS) and Polycarbonate (PC) and another series of polyvinylidene fluoride, PVDF, and low density polyethylene, LDPE, were prepared and characterized for some of their rheological properties.

The blends of a series were prepared by mixing the components, with different weight \% composition, in a molten state using Brabender Plastograph.

Visco-elastic parameters were measured using the capillary rheometer (Melt Index 3/80). Die-swelling rate, (B), was determined for different composition samples and correlated with the end pressure drop, $\left(\Delta P_{e n d}\right)$, the end correction, $(e)$, the apparent shear rate, $\left(\gamma_{\mathrm{a}}\right)$, the apparent shear stress, $\left(\tau_{\mathrm{a}}\right)$, and the length-radius ratio, (L/R). The effects of blending composition on the die-swell rate, $(B)$, the end correction, $(e)$, and the shear strain, $\left(S_{R}\right)$ were also studied for the prepared series of blends.
\end{abstract}

Keywords: PC, ABS, PVDF, LDPE, Elasticity, Blends, Capillary, Swelling.

\section{INTRODUCTION}

The main importance of preparing and using new polymer blends is to meet new market requirements, including applicable technical performances with lower costs. A lot of studies have been made to improve the flow behavior in opaque application of high impact grade $(P C)$ through the addition of a rubbery phase such as (ABS) into the (PC) matrix.

The mixing or blending of polymers can be an efficient way of developing materials with novel or selectively enhanced properties. It is possible to modify some characteristics of polymer blends by varying the composition. Incompatible blends present phase separation as dispersed nodules in the matrix phase, the consequent low adhesion leading to undesirable properties. By controlling the fraction of each component, a resulting polymer with the desired properties can be obtained. Usually, the final objective is to reach a balance between maximum temperature resistance, toughness, etc, and ease of fabrication.

Polycarbonate PC is characterized for its high modulus, high toughness, high impact strength and difficult process-ability, due to its high melt viscosity. Acrylonitrile-Butadiene-Styrene (ABS) is a rubber toughened thermoplastic, characterized by its notch insensitivity and low cost. On the other hand, the ABS

*Address corresponding to this author at the Department of Chemistry, Faculty of Science, Cairo University, Egypt; Tel: +201001649558; Fax: +20224591403; E-mail: refaat_nessim@hotmail.com limitations are: poor flame and chemical resistance, and low thermal stability [1].

The commercialization of PC began in 1958; the production of the PC/ABS blends started on 1977. The addition of $A B S$ to $P C$ minimizes its drawbacks without affecting its superior mechanical properties, and also generates other useful characteristics, such as glossiness and low temperature toughness [2].

$\mathrm{PC}$ and $\mathrm{ABS}$ are fairly similar in polarity, and might be compatible with each other; the ABS grafted rubber (butadiene) particles chains would remain insoluble, but firmly bonded by their styrene-acrylonitrile sidechains, producing good physical properties [3].

The presence of Styrene-Butadiene-Styrene, SBS, copolymer with the polymer blend (PC/ABS) was found to enhance its compatibility [4]. Increase of the molecular weight of (PC) in the polymer blend (PC/ABS) series resulted in low temperature fracture toughness- product but suffering from high melt viscosity [5]. On the other hand, increase of the ABS ratio in the blend series yielded more heterogeneous mixtures [6] and increases the product toughness [7-9].

Low density polyethylene, LDPE, and polyvinylidene fluoride, PVDF, were used as polymeric matrix for composite polymeric materials with high permittivity. These materials have received considerable attention because of their wide use as materials for electrical engineering, high energy storage device, electronics and other industries [10-15]. Steady and oscillatory 
shearing flow properties of compatible and incompatible polymer blend systems were measured, using a cone-and-plate rheometer [16]. The compatible blend systems investigated are blends of two lowdensity polyethylenes, LDPE, having different values of molecular weight and blends of poly- (methyl methacrylate) (PMMA) with poly(vinylidene- fluoride), PVDF. Shen et al., [17] studied the rheological properties of PVDF with different molecular weights, in a molten state using rotational and capillary rheometers and found that PVDF melts behaved in a pseudo plastic manner.

In our work, the rheological properties of $\mathrm{PC} / \mathrm{ABS}$ and LDPE/PVDF series of blends were studied as a function of the composition of the polymer blends.

The rheological properties that characterize the melt elasticity of the polymer blends were previously expressed in terms of the die-swell rate, $\mathrm{B}$, and the shear strain, $S_{R}$, and the end pressure drop, $\Delta \mathrm{P}_{\text {end }}$ and the end correction [18-19].

\section{EXPERMINTAL}

\section{Materials}

(PC, m.wt. avarege $=245000 \mathrm{~g} / \mathrm{mol}$ ) was obtained from GB Plastics; (ABS, 25\% styrene-50\% butadiene25\% acrylonitrile) from LG (Korea); (PVDF, m.wt. avarege $=150000 \mathrm{~g} / \mathrm{mol}$ ) was supplied by AldrichChimie S.a.r.1 (France); and (LDPE, m.wt. avarege = $320000 \mathrm{~g} / \mathrm{mol}$ ) was obtained from Sabic (KSA).

\section{Blends Preparation}

The two blends (PC/ABS) and (PVDF/LDPE) were prepared in different ratios covering the whole composition range, in the molten state using Brabender plastograph in nitrogen atmosphere.

The two types of blends were prepared by mixing the blend components for 20 minutes, under rotational speed of 30 RPM. Mixing temperature for the (PC/ABS) blends was $220^{\circ} \mathrm{C}$ and that of the (PVDF/LDPE) was $190^{\circ} \mathrm{C}$

\section{Apparatus and Methodology}

The elastic properties were measured by using (Melt Indexer $3 / 80)$, at $\left(190^{\circ} \mathrm{C}\right)$ for (PVDF/LDPE) blends and at $\left(220^{\circ} \mathrm{C}\right)$ for (PC/ABS) blends. The rotational speed was $30 \mathrm{RPM}$, round per minute. The extrusion diameter, (D), was measured in millimeters (mm) immediately after the filament was cut and cooled. The values of (D) were then used in the swelling ratio equation:

$B=\frac{D}{D_{0}}$

Where: $(D)$ is the extrusion diameter and $\left(D_{0}\right)$ is the die diameter $(\mathrm{mm})$.

The die swell rate $(B)$ could then be used for calculations of the shear strain $\left(S_{R}\right)$ through the equation:

$S_{R}=B(6 \ln B)^{1 / 2}$

Four different length dies having the same radius were used to determine the end pressure drop, $\left(\Delta P_{\text {end }}\right)$, and the end correction, (e), by plotting the total pressure drop, $(\Delta P)$, versus the length radius ratio, $(L / R)$, and extrapolating the straight line to $\Delta P=0$, where:

$\Delta \mathrm{P}_{\text {end }}=(\Delta \mathrm{P})_{\llcorner/ \mathrm{R}=0}$

and

$\mathrm{e}=(\mathrm{L} / \mathrm{R})_{\triangle \mathrm{P}=0}$

Figure 1. Shows the variation of the pressure drop, $(\triangle P)$, with the length-radius ratio, $(L / R)$, for (PC/ABS), blend having the composition $1: 1$, by weight, at various shear rates $\left(\gamma_{\mathrm{a}}\right)$, at the working temperature, $220^{\circ} \mathrm{C}$. This figure was taken as an example for determining the end pressure drop, $\left(\Delta \mathrm{P}_{\text {end }}\right)$, and the end correction, (e).

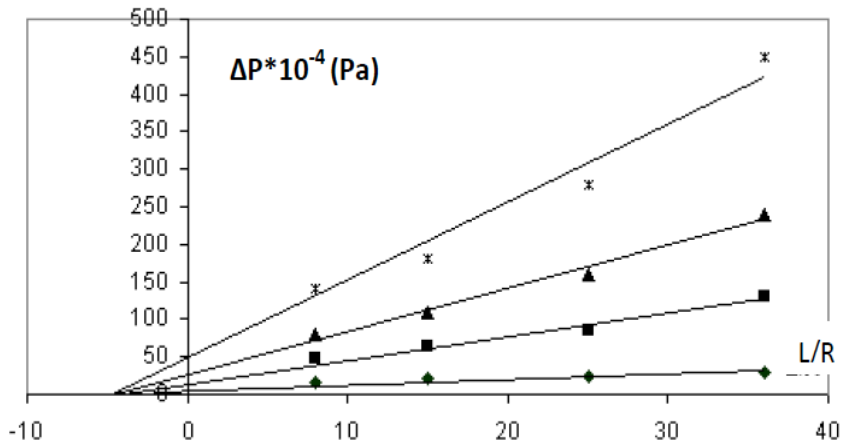

Figure 1: Relation between $(\triangle P)$ and $(L / R)$ for (PC/ABS) $(50 / 50)\left(220^{\circ} \mathrm{C}\right)$.

$\gamma_{\mathrm{a}}\left(\mathrm{s}^{-1}\right)[(\bullet) 1,(\mathbf{\bullet}) 5,(\boldsymbol{\Delta}) 10,(\mathrm{x}) 20]$.

The values of $(\Delta \mathrm{P})$ and $(\mathrm{e})$ are, in turn, used to determine the shear stress, $\left(\tau_{\mathrm{a}}\right)$, using the Bagley correction [20]. 


$$
\tau_{a}=\frac{\left(\Delta P-\Delta P_{e n d}\right)}{2\left(\frac{L}{R}\right)}
$$

or

$$
\tau_{a}=\frac{\Delta P}{2\left(\frac{L}{R}+e\right)}
$$

The apparent shear rate, $\left(\gamma_{a}\right)$, is given by:

$$
\gamma_{a}=\frac{4 Q}{\pi R^{3}}
$$

Where: $(Q)$ represents the volumetric flow rate $\left(\mathrm{cm}^{3} / \mathrm{sec}\right)$ and $(\mathrm{R})$ is the radius of the used die $(\mathrm{cm})$.

Variations of the die swell rate, $(\mathrm{B})$, shear strain, $\left(\mathrm{S}_{\mathrm{R}}\right)$, and the end correction, (e), with blend compositions were studied at constant apparent shear rate, $\left(\gamma_{\mathrm{a}}\right)$, apparent shear stress, $\left(\tau_{\mathrm{a}}\right)$, and the lengthradius ratio $(\mathrm{L} / \mathrm{R})$.

\section{RESULTS AND DISCUSSION}

\section{Relation Between the End Pressure Drop ( $\left.\Delta \boldsymbol{P}_{\text {end }}\right)$ and the Shear Rate $\left(\gamma_{a}\right)$}

Figures 2(a and $\mathbf{b})$ show the variation of $\left(\Delta P_{\text {end }}\right)$ with $\left(\gamma_{a}\right)$ for all blending compositions of the blends (PC/ABS) and (PVDF/LDPE), respectively. Linear relationships confirm the applicability of the power law relation between $\left(\Delta P_{\text {end }}\right)$ and $\left(\gamma_{a}\right)$ :

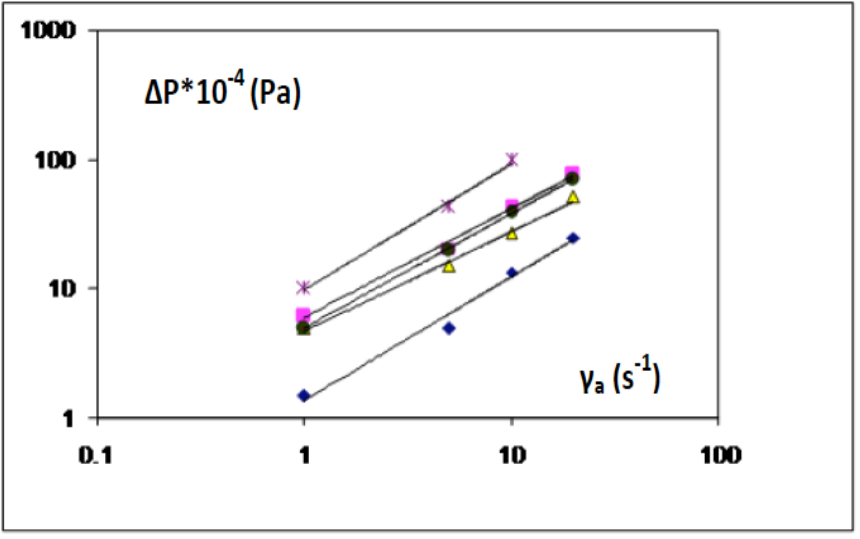

$$
\Delta P_{\text {end }}=\mathrm{c}\left(\gamma_{\mathrm{a}}\right)^{\mathrm{b}}
$$

Where, (b) and (c) are characteristic constants for the material used. The value of (b) reflects the sensitivity of the shear rate $\left(\gamma_{a}\right)$ to elasticity where, the higher the sensitivity of the shear rate $\left(\gamma_{a}\right)$ to elasticity the greater will be the value of the constant (b).

\section{Dependence of the die swell rate (B) on the shear rate $\left(\gamma_{\mathrm{a}}\right)$ and the shear stress $\left(\tau_{\mathrm{a}}\right)$}

Figures $\mathbf{3}(\mathbf{a}$, and $\mathbf{b})$, show the variation of $(B)$ with $\left(\gamma_{a}\right)$ and $\left(\tau_{a}\right)$ respectively for different compositions of the (PC/ABS) blends and Figures $\mathbf{3}(\mathbf{c}$ and $\mathbf{d})$ show the variation of $(B)$ with $\left(\gamma_{a}\right)$ and $\left(\tau_{a}\right)$ respectively for different compositions of the (PVDF/LDPE) blends. (B) increased generally with increasing either) $\left.\gamma_{a}\right)$ or $\left(\tau_{a}\right)$, with an approximately linear relationship between (B) and $\left(\tau_{\mathrm{a}}\right)$ which reflects the applicability of the straight line equation

$B=c+m \tau_{a}$

Where, (c) and $(\mathrm{m})$ are constants related to the melt elasticity.

Variation of the die -swell rate (B) with the end pressure drop $\left(\Delta P_{\text {end }}\right)$, and the end correction (e)

Figures $4(\mathbf{a}$ and $\mathbf{b})$, show the variation of $(B)$ with $\left(\Delta P_{\text {end }}\right)$ and $(e)$, respectively, for different compositions of the studied blends, (PC/ABS) and Figures 4(c and d) show the variation of $(\mathrm{B})$ with $\left(\Delta P_{\text {end }}\right)$ and $(e)$, respectively, for different compositions of the studied blends, (PVDF/LDPE), respectively. It can be seen

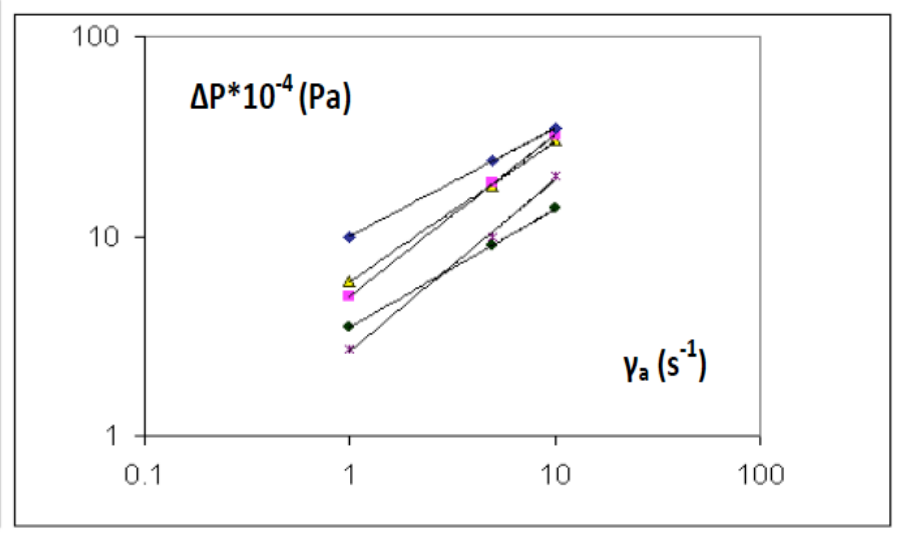

Figure 2: a. Relation between $\left(\Delta \mathrm{P}_{\text {end }}\right)$ and $\left(\gamma_{\mathrm{a}}\right)\left(220^{\circ} \mathrm{C}\right)$.

(PC/ABS)[(•)(0/100), ( $($ ) $(30 / 70),(\Delta)(50 / 50),(\bullet)(70 / 30),(x)(100 / 0)]$.

b. Relation between $\left(\triangle \mathrm{P}_{\text {end }}\right)$ and $\left(\gamma_{\mathrm{a}}\right)\left(190^{\circ} \mathrm{C}\right)$.

(PVDF/LDPE)[(•)(0/100), ( $(30 / 70),(\Delta)(50 / 50),(\bullet)(70 / 30),(x)(100 / 0)]$. 

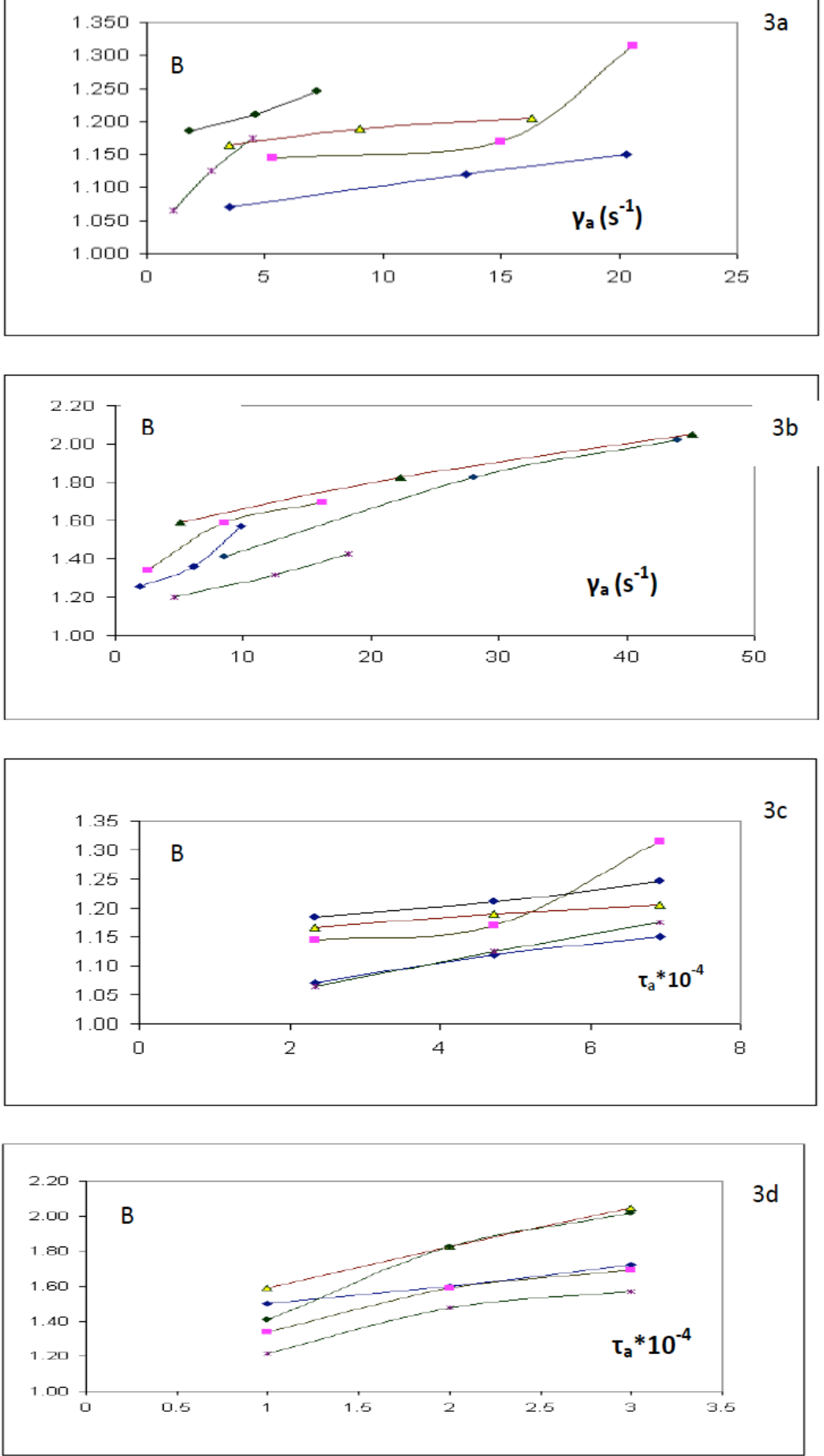

Figure 3: a. Relation between $(B)$ and $\left(\mathrm{Y}_{\mathrm{a}}\right)$ for $(\mathrm{PC} / \mathrm{ABS})\left(\mathrm{L} / \mathrm{R}=8,220{ }^{\circ} \mathrm{C}\right)$. (PC/ABS)[(•)(0/100), ( $(20 / 80),(\triangle)(50 / 50),(\bullet)(80 / 20),(x)(100 / 0)]$.

b. Relation between $(\mathrm{B})$ and $\left(\gamma_{\mathrm{a}}\right)$ for (PVDV/LDPE) $\left(\mathrm{L} / \mathrm{R}=8,190^{\circ} \mathrm{C}\right)$. (PVDF/LDPE) $[(\bullet)(0 / 100),(\varpi)(20 / 80),(\triangle)(50 / 50),(\bullet)(80 / 20),(x)(100 / 0)$.

c. Relation between $(B)$ and $\left(\tau_{\mathrm{a}}\right)$ for (PC/ABS) $\left(\mathrm{L} / \mathrm{R}=8,220{ }^{\circ} \mathrm{C}\right)$. (PC/ABS)[(•)(0/100), ( $(20 / 80),(\triangle)(50 / 50),(\bullet)(80 / 20),(x)(100 / 0)]$. d. Relation between $(B)$ and $\left(\tau_{\mathrm{a}}\right)$ for (PVDF/LDPE) $\left(\mathrm{L} / \mathrm{R}=8,190{ }^{\circ} \mathrm{C}\right)$.

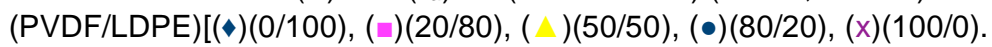

from Figures $4(a$ and $b)$ that $(B)$ increases with increase of $\left(\Delta P_{\text {end }}\right)$, which is being in accordance with previous work. Figures $4(\mathbf{c}$ and $\mathrm{d})$ reveal that $(\mathrm{B})$ also increases with increasing $(e)$, which indicates that there must be a certain correlation between $\left(\Delta P_{\text {end }}\right)$ and $(e)$. 

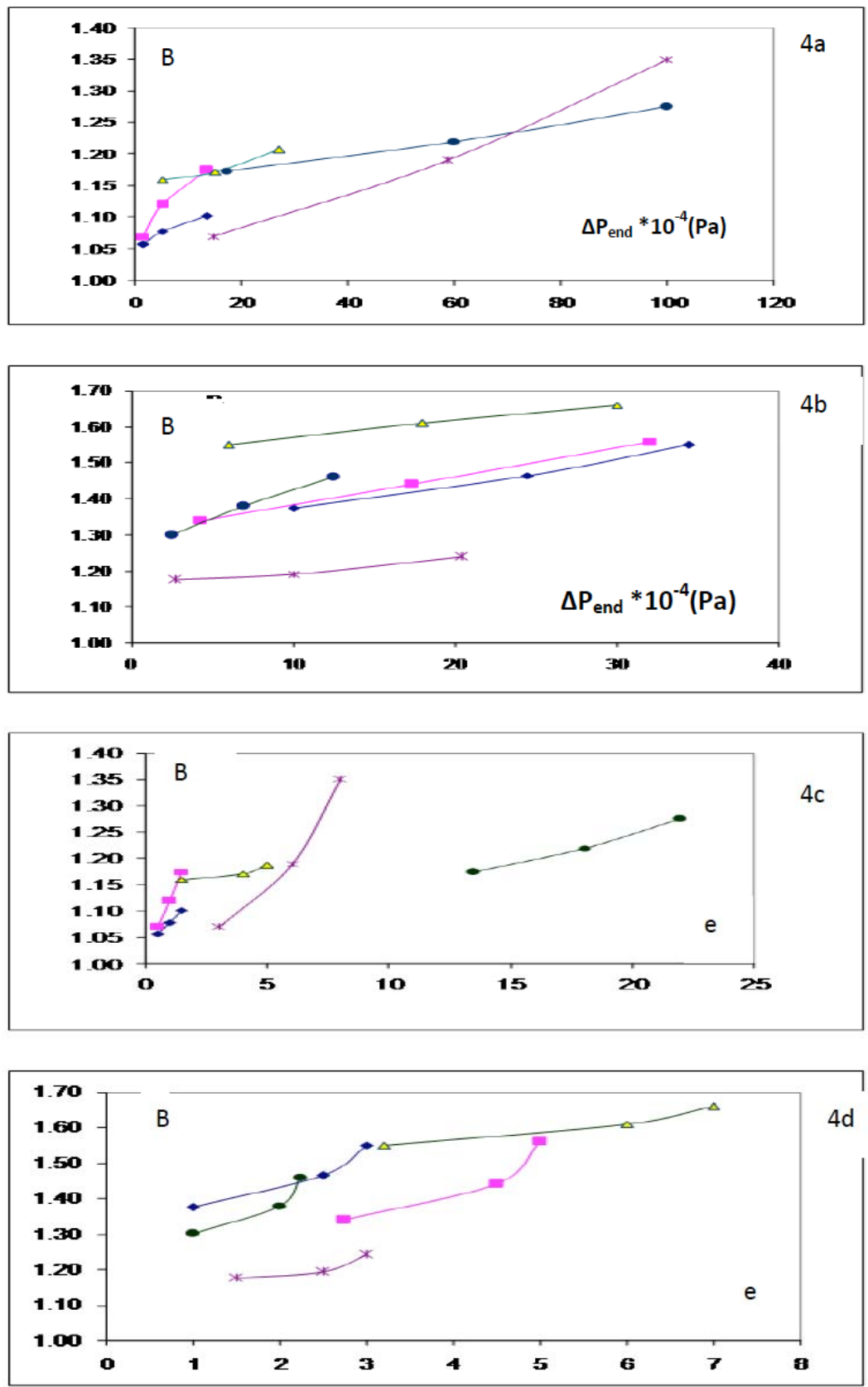

Figure 4: a. Relation between $(B)$ and $\left(\triangle \mathrm{P}_{\text {end }}\right)$ for $(\mathrm{PC} / \mathrm{ABS})\left(220^{\circ} \mathrm{C}\right)$.

$(\mathrm{PC} / \mathrm{ABS})[(\bullet)(0 / 100),(\varpi)(20 / 80),(\triangle)(50 / 50),(\bullet)(80 / 20),(x)(100 / 0)]$.

b. Relation between $(\mathrm{B})$ and $\left(\triangle \mathrm{P}_{\text {end }}\right)$ for (PVDF/LDPE) $\left(190{ }^{\circ} \mathrm{C}\right)$.

(PVDF/LDPE)[( $\bullet)(0 / 100),(\varpi)(20 / 80),(\triangle)(50 / 50),(\bullet)(80 / 20),(x)(100 / 0)]$.

c. Relation between $(\mathrm{B})$ and $(\mathrm{e})$ for $(\mathrm{PC} / \mathrm{ABS})\left(220^{\circ} \mathrm{C}\right)$.

$(\mathrm{PC} / \mathrm{ABS})[(\bullet)(0 / 100),(\varpi)(20 / 80),(\triangle)(50 / 50),(\bullet)(80 / 20),(x)(100 / 0)]$.

d. Relation between (B) and (e) for (PVDF/LDPE) $\left(190^{\circ} \mathrm{C}\right)$.

(PVDF/LDPE)[( $\bullet)(0 / 100),(\varpi)(20 / 80),(\triangle)(50 / 50),(\bullet)(80 / 20),(x)(100 / 0)]$.

\section{Dependence of the Die Swell Rate (B) on the Length-Radius Ratio (L/R)}

Figures $\mathbf{5}(\mathbf{a}$ and $\mathbf{b})$ show the variation of $(B)$ with the $(\mathrm{L} / \mathrm{R})$ ratio for the polymer blends (PC/ABS) and (PVDF/LDPE), respectively, at various compositions. It can be seen from these figures that $(B)$ decreases linearly with increasing the $(L / R)$ ratio for some blending ratios but then it levels-off for other compositions. In both cases we can realize that as the capillary gets longer, the stress relaxation becomes more completed. This will result in reducing the remaining stresses produced in the melt when leaving 

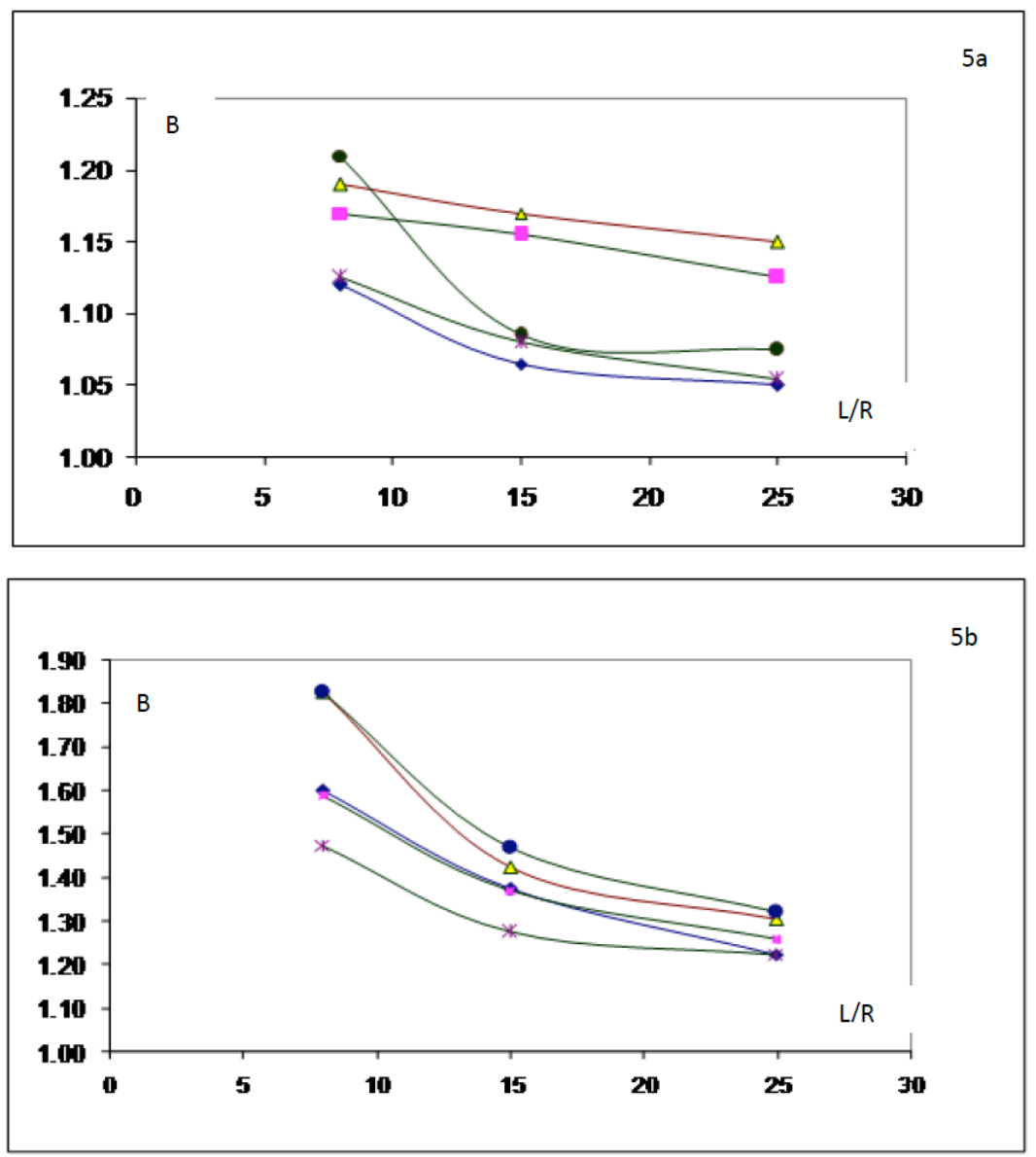

Figure 5: a. Relation between $(B)$ and $(\mathrm{L} / \mathrm{R})$ for $(\mathrm{PC} / \mathrm{ABS})\left(\mathrm{P}=757585(\mathrm{~Pa}), 190^{\circ} \mathrm{C}\right)$. (PC/ABS)[( $)(0 / 100),(\square)(20 / 80),(\triangle)(50 / 50)$, $(\bullet)(80 / 20),(x)(100 / 0)]$.

b. Relation between (B) and (L/R) for (PVDF/LDPE) $(\mathrm{P}=757585(\mathrm{~Pa})$.

$190 \stackrel{\circ}{\circ})$. (PVDF/LDPE)[(•)(0/100), ( $(20 / 80),(\triangle)(50 / 50),(\bullet)(80 / 20),(x)(100 / 0)]$.

he capillary. These stresses include the shear and elongation stresses produced in the flow at the entrance and within the die. Accordingly, the die swell $(B)$ is decreased with increasing the die $(L / R)$ ratio.

Effect of Composition of the Polymer Blend (PC/ABS) on the Die Swell Rate (B), Shear Strain $\left(S_{R}\right)$ and the End Correction (e), at Fixed Shear Rate $\left(\gamma_{\mathrm{a}}\right)$ and Shear Stress $\left(\tau_{\mathrm{a}}\right)$ values

Figures $\mathbf{6}(\mathbf{a}, \mathbf{b}$, and $\mathbf{c})$ show the variation of $(B),\left(S_{R}\right)$ and (e), respectively, with the blending ratio of the polymer blend (PC/ABS) at fixed shear rate $\left(\gamma_{a}\right)$ values; while Figures $\mathbf{6}(\mathbf{d}$ and $\mathbf{e})$ show the variation of $(B),\left(S_{R}\right)$ and $(e)$, respectively, with the blending ratio of the same polymer blend at fixed shear stress $\left(\tau_{\mathrm{a}}\right)$ values. All of these plots, $6(a, b, c, d$ and e) pass through two maxima at the blending compositions (30/70) and $(80 / 20)$ and a minimum at $(60 / 40)$ of (PC/ABS), by weight. These observations could be considered as main characteristics of the polymer blend elasticity.
Effect of Composition of the Polymer Blend (PVDF/LDPE) on Thee Die Swell Rate (B), Shear Strain $\left(S_{R}\right)$ and the End Correction (e) at Fixed Shear Rate $\left(\gamma_{\mathrm{a}}\right)$ and Shear Stress $\left(\tau_{\mathrm{a}}\right)$ values

Figures $\mathbf{7}(\mathbf{a}, \mathbf{b}$ and $\mathbf{c})$ show the variation of $(B),\left(S_{R}\right)$ and $(\mathrm{e})$, respectively, with the blending ratio of the polymer blend (PVDF/LDPE) at fixed shear rate $\left(\gamma_{a}\right)$ values; while Figures $\mathbf{7}(\mathbf{d}$ and $\mathbf{e})$ show the variation of $(B),\left(S_{R}\right)$ and (e), respectively, with the blending ratio of the same polymer blend at fixed shear stress $\left(\tau_{\mathrm{a}}\right)$ values.

During intensive mixing in screw extruder, the least viscous molten polymer, in a sample of $1: 1$ ratio by weight, of the two polymers (PVDF) and (LDPE), will form an easily deformable matrix as a continuous phase; while the more viscous polymer will form a difficultly deformable, dispersed phase. Each component has its own elastic properties and can recover a part of its internal energy during melt flow. The dispersed phase can recover a larger part of its 

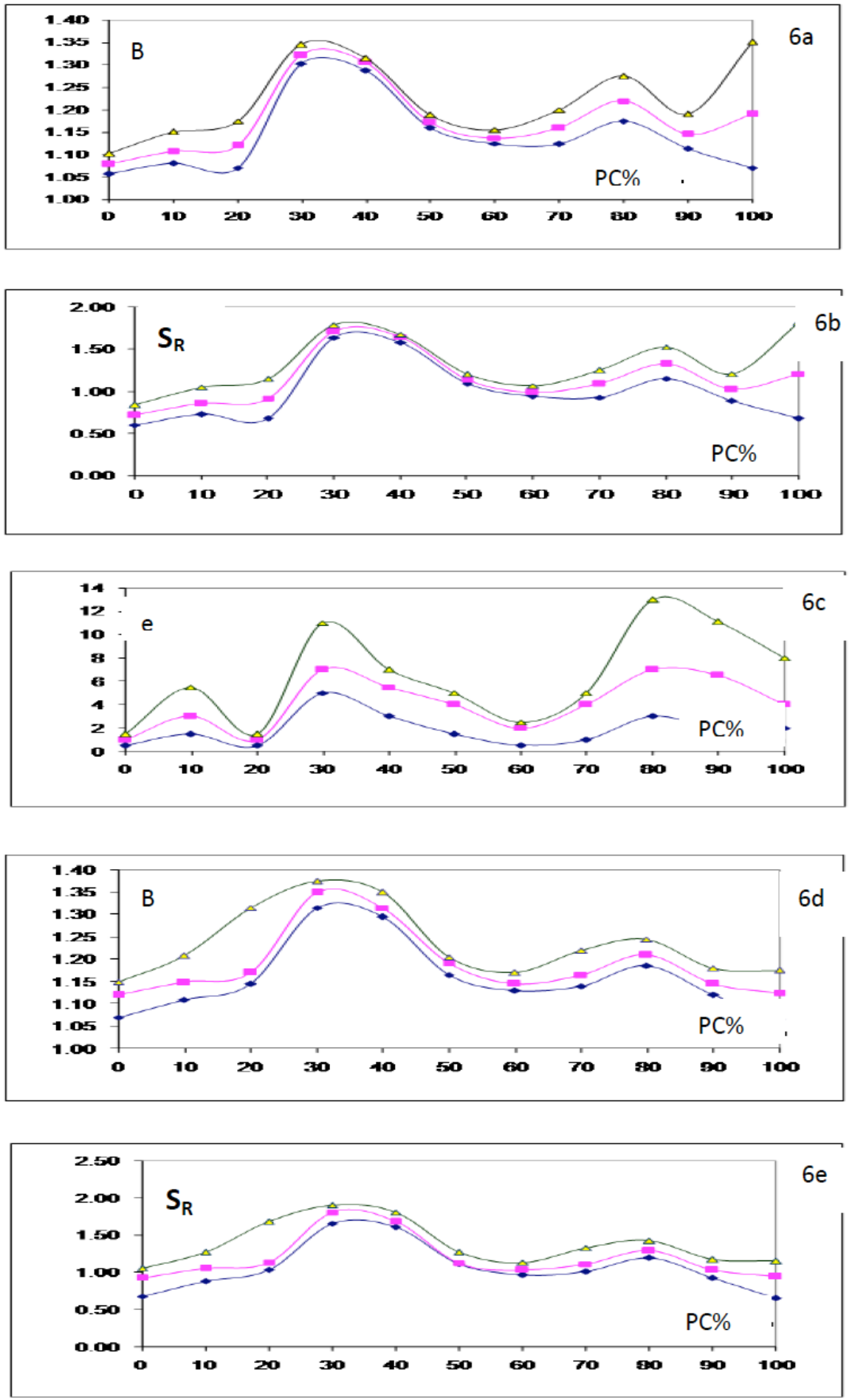

Figure 6: a. Effect of blending ratio of $(P C / A B S)$ on $(B)\left(L / R=8,220^{\circ} \mathrm{C}\right)$.

$\gamma_{\mathrm{a}}\left(\mathrm{s}^{-1}\right)[(\bullet) 1,(\square) 5,(\Delta) 10]$.

b. Effect of blending ratio of $(P C / A B S)$ on $\left(S_{R}\right)\left(L / R=8,220^{\circ} \mathrm{C}\right)$.

$\gamma_{\mathrm{a}}\left(\mathrm{S}^{-1}\right)[(\diamond) 1,(\square) 5,(\triangle) 10]$.

c. Effect of blending ratio of $(\mathrm{PC} / \mathrm{ABS})$ on $(\mathrm{e})\left(220^{\circ} \mathrm{C}\right)$.

$\gamma_{a}\left(S^{-1}\right)[(\diamond) 1,(\square) 5,(\Delta) 10]$.

d. Effect of blending ratio of (PC/ABS) on $(B)\left(L / R=8,220^{\circ} \mathrm{C}\right)$.

$\tau_{\mathrm{a}}{ }^{*} 10^{-4}(\mathrm{~Pa})[(\diamond) 2.3,(-) 4.7,(\triangle) 6.9]$.

e. Effect of blending ratio of (PC/ABS) on $\left(S_{R}\right)(L / R=8,220 \stackrel{\circ}{\circ})$.

$\tau_{\mathrm{a}}{ }^{*} 10^{-4}(\mathrm{~Pa})[(\diamond) 2.3,(\square) 4.7,(-) 6.9]$. 

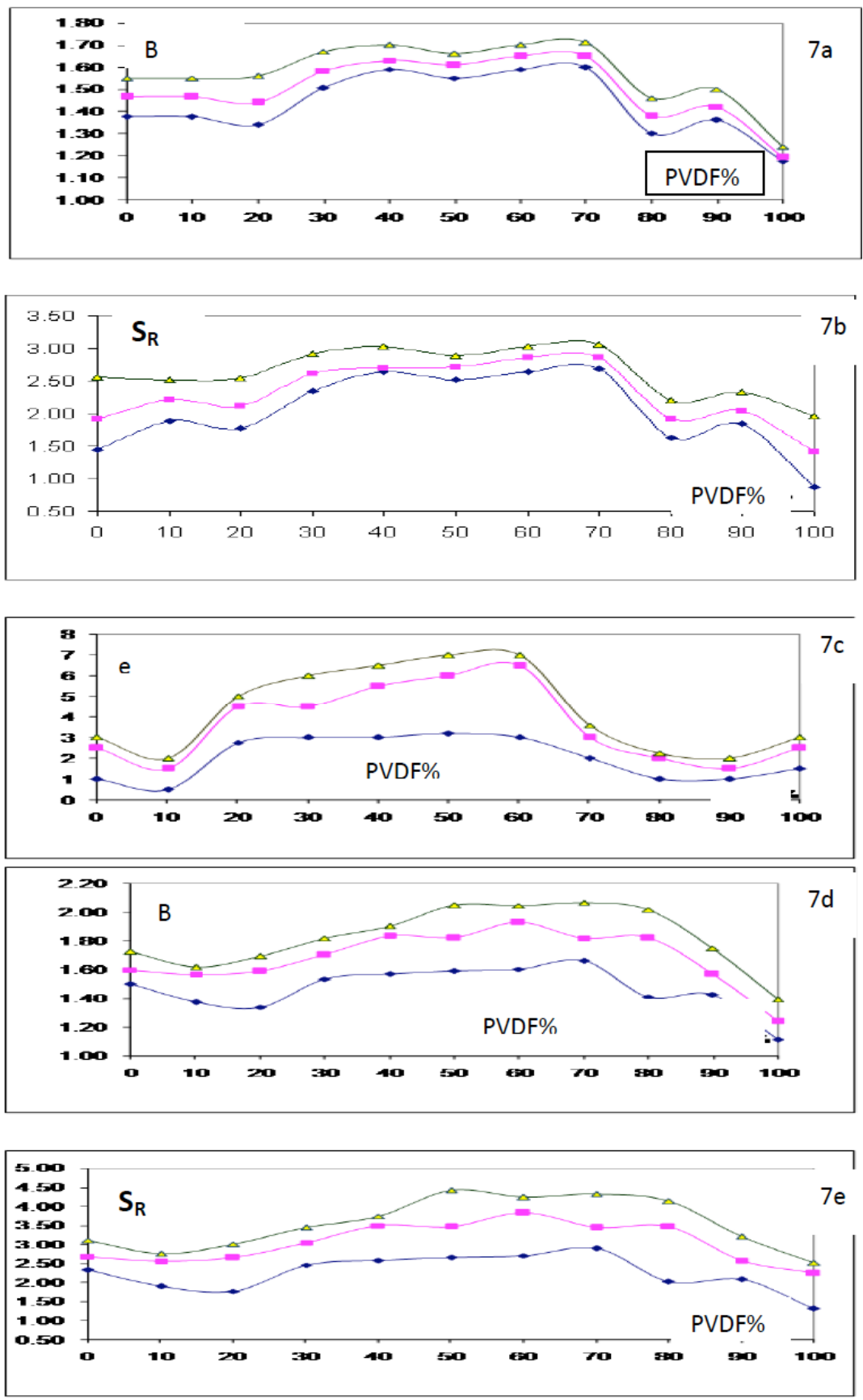

Figure 7: a. Effect of blending ratio of (PVDF/LDPE) on (B) $\left(\mathrm{L} / \mathrm{R}=8,190{ }^{\circ} \mathrm{C}\right)$.

$\gamma_{\mathrm{a}}\left(\mathrm{s}^{-1}\right)[(\bullet) 1,(\boxplus) 5,(\triangle) 10]$.

b. Effect of blending ratio of (PVDF/LDPE) on $\left(S_{R}\right)(L / R=8,190 \stackrel{\circ}{\circ})$.

$\gamma_{\mathrm{a}}\left(\mathrm{S}^{-1}\right)[(\bullet) 1,(\varpi) 5,(\triangle) 10]$.

c. Effect of blending ratio of (PVDF/LDPE) on (e) $\left(190^{\circ} \mathrm{C}\right)$.

$\gamma_{\mathrm{a}}\left(\mathrm{S}^{-1}\right)[(\bullet) 1,(\square) 5,(\triangle) 10]$.

d. Effect of blending ratio of (PVDF/LDPE) on (B) (L/R=8, $\left.190^{\circ} \mathrm{C}\right)$.

$\tau_{\mathrm{a}}{ }^{*} 10^{-4}(\mathrm{~Pa})[(\bullet) 2.3,(\varpi) 4.7,(\triangle) 6.9]$.

e. Effect of blending ratio of (PVDF/LDPE) on $\left(\mathrm{S}_{\mathrm{R}}\right)\left(\mathrm{L} / \mathrm{R}=8,190{ }^{\circ} \mathrm{C}\right)$.

$\tau_{\mathrm{a}}{ }^{*} 10^{-4}(\mathrm{~Pa})[(\triangleleft) 2.3,(\varpi) 4.7,(\triangle) 6.9]$.

internal energy than the matrix, where the former will be deformed without contacting the die wall, while the continuous phase will be deformed through the die wall and hence it will lose a part of its energy to overcome the friction forces at the die wall. The dispersed phase will be maximum in that blend having the composition 
ratio $1: 1$, which will recover a larger part of the internal energy than the other blend compositions. Based on this concept, Figures $7(\mathbf{a}-\mathbf{e})$ show maximum $(B),\left(S_{R}\right)$ and $(e)$ values at $1: 1$ blending ratio at fixed $\left(\gamma_{a}\right)$ and $\left(\tau_{a}\right)$ values.

The whole phenomena which were observed in the studied polymer blends (PC/ABS) and (PVDF/LDPE), can be attributed to the amount of elastic deformation energy stored in the melt flow and its variation due to the difference in the visco-elastic properties of the two phases.

\section{CONCLUSION}

Through this work, it was found that the end pressure drop $\left(\Delta \mathrm{P}_{\text {end }}\right)$ increases linearly with increasing the apparent shear rate $\left(\gamma_{a}\right)$ which suggests the applicability of the power law between the two variables. The die swell ratio $(B)$ for the studied blends (PC/ABS) and (PVDF/LDPE) was found to increase as the shear rate $\left(\gamma_{a}\right)$ and the shear stress $\left(\tau_{a}\right)$ increases. Also, (B) was found to increase with increasing either the end pressure drop $\left(\Delta \mathrm{P}_{\text {end }}\right)$ or the end correction (e), which indicates the presence of an interconnection between $\left(\Delta \mathrm{P}_{\text {end }}\right)$ and $(\mathrm{e})$. The decrease of the die swell ratio $(B)$ with increasing the length-radius ratio $(L / R)$ was attributed to the presence of more stress relaxation in the longer die. The same trend of variations of both $(B)$ and $(e)$ with the blending ratio of the two blends reveals that the concept of the end correction, (e), may be used for characterizing the polymer blends in terms of their elastic properties.

\section{ACKNOWLEDGEMENT}

The author would like to thank the researchers in laboratory of plastic materials rheology, Faculty of science and technology, University of Saint-Etienne (France) for their aid in this work.

The author would like to appreciate the help of Sabic-KSA through supplying LDPE as a working material without any mutual financial gain.

\section{REFERENCES}

[1] Utracki LA. Polymer Blends Handbook. Kluwer Academic Publisher, Amsterdam 2002.
[2] Nordgren F, Nyquist $M$. FE-Modelling of PC/ABSExperimental Tests and Simulations. Master's Dissertation, Division of Solid Mechanics, Lund University, Lund 2006.

[3] Utracki LA, Favis BD. Polymer Alloys and Blends. In: P. N. Cheremisin off, Ed., Handbook of Polymer Science and Technology, Marcel Dekker, Inc., New York 1989; pp. 121201.

[4] Tasdemir M. J Appl Polym Sci 2004; 93: 2521-27. http://dx.doi.org/10.1002/app.20708

[5] Wu JS, Shen SC, Chang FC. J Appl Polym Sci 1993; 50: 1379-1389. http://dx.doi.org/10.1002/app.1993.070500809

[6] Fathi E, Liye Z, Run F, Hangquan L. Polym J 2004; 45: 671924 http://dx.doi.org/10.1016/i.polymer.2004.07.022

[7] Kurauchi T, Ohta T. J Mater Sci 1984; 19: 1699-709. http://dx.doi.org/10.1007/BF00563068

[8] Ishikawa M, Chiba I. Polym J 1990; 31: 1232-38 http://dx.doi.org/10.1016/0032-3861(90)90213-I

[9] Wu JS, Shen SC, Chang FC. Polym J 1994; 26: 33-42. http://dx.doi.org/10.1295/polymj.26.33

[10] Das-Gupta DK, Doughty K. Polymer-ceramic composite materials with high permittivities. Thin Solid Films 1988; 158 93-105.

http://dx.doi.org/10.1016/0040-6090(88)90306-9

[11] Gefle OS, Lebedev SM, Zatulii Al, et al. Influence of highpermittivity barriers on the treeing process characteristics for PMMA. Russian J Electricity 1988; 10: 65-67.

[12] Gefle OS, Lebedev SM, Pokholkov YP. Barrier Effect in Dielectrics, TML-Press, Tomsk 2007.

[13] Chan HLW, Chen Y, Choy CL. Thermal hysteresis in the permittivity and polarization of lead zirconate titanate/vynilidenefluoride-trifluoroethylene 0-3 composites, IEEE Trans Diel Electr Insul 1996; 3: 800-805. http://dx.doi.org/10.1109/94.556562

[14] Gefle OS, Lebedev SM, Pokholkov YP. The barrier effect in dielectrics. The role of interfaces in the breakdown of inhomogeneous dielectrics. IEEE Trans Diel Electr Insul Vol. 2005; 12: 537-55. http://dx.doi.org/10.1109/TDEl.2005.1453459

[15] Chan HLW, Chan WK, Zhang Y, et al. Pyroelectric and piezoelectric properties of leadtitanate/polyvinylidene fluoride-trifluoroethylene 0-3 composites. IEEE Trans Diel Electr Insul 1998; 5: 505-12. http://dx.doi.org/10.1109/94.708265

[16] Chuang H-K, Han CD. J Appl Polym Sci 1984; 29: 2205-29. http://dx.doi.org/10.1002/app.1984.070290625

[17] Shen L, Song Y, Qiao Y, Zhang F, Zheng Q. Chin J Appl Polym Sci 2008; 26: 639-44.

[18] Han CD, Yu TC. J Polym Eng Sci 1972; 12: 81-90. http://dx.doi.org/10.1002/pen.760120203

[19] Liang JZ. J Polym Test 2002; 21: 69-74. http://dx.doi.org/10.1016/S0142-9418(01)00050-2

[20] Bagley EB. J Appl Phys 1957; 28: 624-27. http://dx.doi.org/10.1063/1.1722814 